PONTIFÍCIA UNIVERSIDADE CATÓLICA DO RIO DE JANEIRO

A relação do comportamento do consumidor com os impactos ambientais relacionados à alimentação

Pietra Marques Lucchesi

Trabalho de Conclusão de Curso

CENTRO DE CIÊNCIAS SOCIAIS - CCS

DEPARTAMENTO dE AdMINISTRAÇÃo

Graduação em Administração de Empresas 


\title{
Pietra Marques Lucchesi
}

\section{A relação do comportamento do consumidor com os impactos ambientais relacionados à alimentação}

\author{
Trabalho de Conclusão de Curso
}

Trabalho de Conclusão de Curso, apresentado ao programa de graduação em Administração da PUC-Rio como requisito parcial para a obtenção do título de graduação em Administração.

Orientadora: Vivian Steinhäuser

Rio de Janeiro, junho de 2019. 


\section{Agradecimentos}

Agradeço, com todo o meu coração, à minha família. Eles sempre batalharam muito para nada me faltar e sem eles eu nunca chegaria onde estou.

Em especial, gostaria de agradecer à minha mãe, Renata, que sempre fez tudo por mim e sempre me acolheu, me acalmando e dizendo que tudo daria certo no final.

Agradeço a todos os amigos que fiz durante a faculdade, que deixaram tudo mais leve e que com certeza levarei para toda a minha vida.

Agradeço à minha amiga Ana Carolina Cosenza por estar comigo desde o primeiro ao último dia da faculdade, sempre do meu lado nos melhores e piores momentos.

Agradeço a todos os professores que me ensinaram tanto durante todos esses anos.

Agradeço por todas as pessoas que já passaram na minha vida e me acrescentaram de alguma forma.

Por fim, agradeço à minha orientadora, Vivian Steinhäuser, por toda compreensão e paciência. 


\section{Resumo}

LUCCHESI, Pietra. A relação do comportamento do consumidor com os impactos ambientais relacionados à alimentação. Rio de Janeiro, 2019. Número de páginas $p$. Trabalho de Conclusão de Curso - Departamento de Administração. Pontifícia Universidade Católica do Rio de Janeiro.

Os impactos das ações humanas no meio ambiente estão cada vez mais evidentes e preocupantes, mostrando que o planeta não está mais suportando a produção excessiva, exploratória e as formas de consumo. Um dos principais motivos desses problemas ambientais está relacionado à alimentação. Nesse contexto, o presente estudo analisa se há mudança no comportamento do consumidor quando este possui o conhecimento dos impactos negativos causados pela sua alimentação. São explorados diversos conceitos referentes ao tema, como comportamento do consumidor, consumo consciente, sistemas agrícolas, Revolução Verde e alimentação sustentável.

Palavras-chave

Comportamento do consumidor, alimentação, problemas ambientais, consumo consciente. 


\section{Abstract}

LUCCHESI, Pietra. The relation between consumer habits and environmental impacts associated with food consumption. Rio de Janeiro, 2019. Número de páginas p. Trabalho de Conclusão de Curso - Departamento de Administração. Pontifícia Universidade Católica do Rio de Janeiro.

The impact of human action in the environment is increasingly evident and alarming, demonstrating that the indiscriminate overproduction of food needs to come to a halt. That being said, one of the biggest reasons of these environmental problems is associated with food consumption. In this regard, this study analyses if there is change in consumer habits when consumers are aware of the negative impacts caused by the way they consume food. That being said, many theories related to the subject are approached, such as consumer habits, conscious consumerism, agricultural systems, the Green Revolution and healthy food consumption.

Keywords

Consumer Habits, Food Consumption, Environmental Problems, Conscious Consumerism. 


\section{Sumário}

$\begin{array}{ll}\text { 1. Introdução } & 09\end{array}$

1.1. Introdução ao tema e ao problema do estudo 09

1.2. Objetivo do estudo 11

1.3. Delimitação e foco do estudo 11

1.4. Justificativa e relevância do Estudo 12

$\begin{array}{lr}\text { 2. Referencial teórico } & 13\end{array}$

2.1. Comportamento do consumidor 13

2.2. Consumo consciente 14

$\begin{array}{ll}\text { 2.2.1. Ecoeconomia } & 14\end{array}$

2.2.2. Consumo verde 15

2.2.3. Consumo sustentável 15

$\begin{array}{lr}\text { 2.3. Revolução verde } & 16\end{array}$

$\begin{array}{ll}\text { 2.4. Sistemas agrícolas } & 16\end{array}$

$\begin{array}{lr}\text { 2.4.1. Sistema agrícola intensivo } & 17\end{array}$

$\begin{array}{ll}\text { 2.4.2. Sistema agrícola extensivo } & 17\end{array}$

$\begin{array}{ll}\text { 2.4.3. Sistemas agrícolas alternativos } & 17\end{array}$

$\begin{array}{ll}\text { 2.5. Alimentação sustentável } & 18\end{array}$

3. Metodologia de estudo 19

3.1. Coleta de dados 19

$\begin{array}{ll}\text { 3.2. Fontes de informação selecionadas } & 19\end{array}$

3.3. Procedimentos e instrumentos utilizados 21

3.4. Forma de tratamento e análise dos dados 21

3.5. Limitações do método $\quad 21$

4. Apresentação e análise dos resultados 23

4.1. Questões ambientais e atitudes sustentáveis de consumo 23

4.2. Relação da alimentação com os problemas ambientais 24 
4.3. Mudança no comportamento do consumidor em relação à dieta alimentar

4.4. Papel do consumidor em relação aos produtos orgânicos e desperdício de alimentos

5. Conclusões 30

5.1. Sugestões e recomendações para novos estudos 32

6. Referências Bibliográficas 33

$\begin{array}{ll}\text { Anexos } & 36\end{array}$ 
Índice de Tabelas

Tabela 1 - Perfil dos entrevistados. 


\section{Introdução}

\subsection{Introdução ao tema e ao Problema de Estudo}

A economia sempre foi vista como um progresso linear e quantitativo, com a visão de que os recursos naturais sempre seriam ilimitados. Entretanto, ao longo do tempo, todos puderam perceber que esse processo incessante é insustentável e autodestrutivo e que o principal desafio atual é a preocupação de manter o equilíbrio no tripé econômico, social e ambiental (Friend, 2009), mostrando que cada vez mais os problemas ambientais crescem como consequência.

De acordo com a Organização das Nações Unidas para Alimentação e Agricultura (FAO), os cinco principais problemas ambientais são a poluição do ar e mudanças climáticas, o desmatamento, a extinção de espécies, a degradação do solo e a superpopulação. Entre estes cinco problemas, quatro deles estão diretamente relacionados à forma de se alimentar que a sociedade adquiriu nas últimas décadas.

Em relação à poluição do ar, a atividade que mais emite metano e prejudica é a criação de gado, disparando na frente da queima de combustíveis fósseis, que a maioria das pessoas acredita ser o principal responsável. Estas emissões de metano estão vinculadas ao fenômeno de fermentação durante a digestão desses animais e também ao armazenamento de esterco. A alimentação da sociedade inclui cada vez mais carne e produtos de origem animal, o que aumenta progressivamente a produção e, consequentemente, os problemas ambientais.

Outro impasse que o consumo de produtos animais gera é o desmatamento de florestas, muitas vezes de forma ilegal, para a criação de gado e plantação de soja para alimentá-los. De acordo com a FAO, mais de $70 \%$ da Amazônia já teve suas terras desmatadas em decorrência do agronegócio, principalmente para o mercado internacional. Além disso, o lixo que a pecuária produz é maior que o lixo gerado pelas indústrias, o lixo civil e a construção juntos.

As escolhas alimentares também são as maiores responsáveis pela extinção de diversas espécies de animais. Também segundo a FAO, 30\% das espécies de peixe estão em extinção por conta da pesca excessiva, em que a grande maioria do que é pescado acabam sendo animais que se enroscam nas redes de pesca. Além disso, de acordo com a 
Agência de Notícias de Direitos Animais (ANDA), o crescente comércio de carne de animais selvagens já colocou mais de 300 espécies à beira da extinção.

Outra informação referente à extinção de animais é em relação às abelhas, por conta dos agrotóxicos. As abelhas são responsáveis pela polinização da maioria dos ecossistemas do planeta, promovendo a reprodução de diversas espécies vegetais. Segundo a FAO, 75\% dos cultivos destinados à alimentação humana dependem das abelhas, o que mostra que, caso sejam extintas, a vida humana também corre risco de extinção. Só neste ano já foram liberados mais de 197 novos agrotóxicos no Brasil e, em decorrência disso, mais de 500 milhões de abelhas morreram.

E, por fim, em relação à degradação do solo, segundo a Global Soil Forum, a quantidade de terra agricultável já diminuiu 50\% nos últimos 50 anos devido ao uso excessivo de substâncias químicas. O uso de fertilizantes, inseticidas e herbicidas na produção agropecuária para aumentar a escala de produção contamina tanto o solo quanto as águas, uma vez que, penetrando o solo, uma parte atinge o lençol freático e contamina o aquífero e a outra é levada para rios, lagos e mares.

Além destes quatro problemas ambientais apresentados, a alimentação é a principal causa de vários outros. As escolhas dos alimentos têm a maior influência em relação ao desperdício de água potável. Um estudo feito pela Sabesp, empresa que detém a concessão dos serviços públicos de saneamento básico do estado de São Paulo, mostra que produtos de origem animal são os alimentos que mais utilizam água na sua produção. De acordo com esse estudo, para fazer apenas um quilo de carne bovina, a quantidade de água consumida é igual a 17.100 litros. Além disso, para fazer um quilo de manteiga e um quilo de queijo, a quantidade necessária é igual a 18.000 litros e 5.280 litros, respectivamente, enquanto para fazer um quilo de arroz, a quantidade é igual a 2.500 litros.

Outra questão relacionada à alimentação é o desperdício e perda de alimento. A fome é um dos principais problemas que atinge diversos países, crescendo a cada dia, porém, se houvesse um maior cuidado na produção, colheita e distribuição, isso seria resolvido, uma vez que apenas $10 \%$ de tudo que é produzido chegam aos consumidores. Além disso, de acordo com a FAO, apenas um quarto do que é desperdiçado nos Estados Unidos e na Europa daria para alimentar 800 milhões de pessoas.

Além do desperdício na produção, colheita e distribuição, ocorre o desperdício na hora do preparo, uma vez que quase sempre o alimento não é usado integralmente e cascas, talos e folhas de verduras e frutas, por exemplo, sempre vão parar no lixo.

Olhando para todos esses problemas e sua relação direta com a alimentação, o presente estudo espera obter a resposta do seguinte questionamento: As pessoas mudam seus hábitos alimentares quando sabem dos problemas ambientais que estes podem causar? 


\subsection{Objetivo do Estudo}

O objetivo do estudo é analisar se há mudança no comportamento do consumidor em relação às suas práticas alimentares quando há o conhecimento dos diversos impactos negativos ao meio ambiente.

\subsection{Delimitação e Foco do Estudo}

O principal foco do presente estudo será a análise do comportamento do consumidor em relação à sua alimentação, verificando se os mesmos julgam importantes os impactos ambientais em relação a esse consumo.

Além disso, o estudo também terá como foco a análise do nível de conhecimento dos consumidores em relação aos problemas ambientais causados pela maneira que se alimentam.

Apesar de existirem inúmeros problemas ambientais, como apresentado anteriormente na introdução, estes não serão estudados a fundo, uma vez que não se tem a intenção de mostrar dados sobre os problemas e sim analisar sobre o que o consumidor já tem ou não conhecimento.

Os dados analisados são referentes a jovens e adultos, sem distinção de classe social. Por ser um tema relacionado a algo que todos consomem, e o intuito é realmente analisar o comportamento e nível de conhecimento, o estudo não terá restrição e limitação referente à idade, grau de escolaridade e renda. Os entrevistados serão dos estados de São Paulo, Minas Gerais e Rio de janeiro, por questão de acessibilidade. Além disso, os entrevistados da segunda etapa, caracterizada por uma entrevista qualitativa, são pessoas que conhecem setenta por cento dos dados apresentados no questionário da primeira etapa referentes ao tema de estudo. 


\subsection{Justificativa e Relevância do Estudo}

A apresentação das informações e conclusão deste estudo poderá servir de base para futuros estudos sobre assuntos relacionados à alimentação e aos impactos ambientais relacionados a isso.

Como um dos focos é analisar o nível de conhecimento e como os consumidores têm mudado seu comportamento de compra ao longo dos anos, este estudo poderá ser considerado de interesse para empresas, principalmente para empresas do ramo da alimentação e sustentabilidade.

Além disso, a relevância deste estudo está relacionada ao crescente envolvimento da sociedade em querer mudar suas atitudes para que causem o mínimo de impacto possível ao meio ambiente e reverter a situação crítica em que o planeta se encontra depois de tantos anos de descuido e exploração.

Por fim, este estudo poderá apresentar uma considerável relevância acadêmica, uma vez que contribuirá para pesquisadores e estudantes que tenham interesse em se aprofundar mais nesse assunto, que está ganhando cada vez mais visibilidade. 


\section{Referencial Teórico}

Este capítulo do estudo apresenta a revisão da literatura que serviu como base para a pesquisa realizada. Sendo assim, para uma melhor compreensão, inicialmente será abordado o comportamento do consumidor. Em seguida, serão apresentados temas relacionados ao consumo consciente, englobando a ecoeconomia, o consumo verde e o consumo sustentável. Por fim, serão abordados temas relacionados diretamente com a alimentação, como: Revolução Verde, sistemas agrícolas e alimentação sustentável.

\subsection{Comportamento do Consumidor}

Cada pessoa pensa e sente de um jeito único, o que torna cada vez mais difícil para as empresas entenderem seus consumidores e o que eles realmente necessitam e desejam. Desse modo, para uma melhor percepção, surgiu dentro do Marketing um tema abordando esses assuntos: o comportamento do consumidor.

O campo de comportamento do consumidor abrange uma área muito extensa, estudando os processos envolvidos quando as pessoas selecionam, compram, usam ou descartam os produtos, serviços, ideias e experiências, satisfazendo necessidades e desejos. (Solomon, 2016).

\footnotetext{
"Simplesmente falando, o comportamento do consumidor é tradicionalmente pensado como o estudo de 'por que as pessoas compram', sob a premissa de que é mais fácil desenvolver estratégias para influenciar os consumidores depois que entendemos por que as pessoas compram certos produtos ou marcas." (Blackwell, Miniard e Engel, 2005).
}

Dessa forma, o comportamento do consumidor surgiu principalmente para as empresas entenderem primeiro o porquê do seu público-alvo comprar. Posteriormente, segundo Blackwell, Miniard e Engel (2005), as empresas passaram a analisar além da compra e passaram a entender o processo de consumo, englobando as ações e pensamentos posteriores à ação da compra, o que permitia um estudo mais amplo e aprofundado.

O estudo do comportamento do consumidor, por ser um processo de acompanhamento das mudanças das percepções de seus consumidores, deve ser sempre o foco principal das estratégias de marketing de uma empresa. 


\subsection{Consumo Consciente}

De acordo com o Ministério do Meio Ambiente (2012), a humanidade já consome mais de $30 \%$ dos recursos naturais do que a capacidade de renovação da Terra e, caso o comportamento da sociedade não mude, até 2050 serão necessários dois planetas Terra para suprir todas as nossas necessidades como água e alimento.

Dessa forma, é necessária a consciência de que a forma como consumimos sempre vai impactar o meio ambiente, sendo positiva ou negativamente. As escolhas de consumo devem começar a ser feitas tendo como prioridade o seu impacto, levando a escolhas mais conscientes. O consumo consciente tem como objetivo pequenas mudanças no dia a dia que gerarão um grande resultado no futuro.

Segundo o Instituto Akatu (2008), "Consumir conscientemente é fazer do ato de consumo um ato de cidadania, ao considerar o impacto da sua compra e uso de produtos e serviços sobre a sociedade e o meio ambiente"

Segundo o Ministério do Meio Ambiente (2005), a expressão "consumo consciente" surgiu para incluir também aspectos sociais, além dos ecológicos. Dessa forma, o consumo consciente requer que os consumidores tenham compromisso ético e responsabilidade quanto aos impactos sociais e ambientais que suas escolhas e comportamentos podem causar em ecossistemas e a outros grupos sociais.

Para melhor entender o que significa ter um consumo consciente, o qual terá como ênfase as questões ambientais, serão abordados três temas, são eles: ecoeconomia, consumo verde e consumo sustentável.

\subsubsection{Ecoeconomia}

A ecoeconomia é um termo criado pelo analista do ambiente, Lester Brown (2003) para evidenciar a proposta de uma economia que respeita a natureza, tendo como princípio a produção sustentável e não a produção excessiva e autodestrutiva. É a economia que supre nossas necessidades sem deixar consequências negativas para as gerações futuras, afirmando que se não houver mudanças na economia global, o planeta não irá aguentar, tanto em questões ambientais como em questões econômicas. 
Dessa forma, podemos entender que para que seja feito um progresso, política e meio ambiente devem andar juntos e em equilíbrio e não um em detrimento do outro.

\subsubsection{Consumo Verde}

De acordo com Cooper (2002), o consumo verde é o "padrão de consumo através da compra e uso dos bens e serviços que atendam às necessidades básicas das pessoas em conjunto com a minimização da degradação ambiental".

Consumo verde, de acordo com o Ministério do Meio Ambiente (2005) é aquele em que o consumidor, além de buscar melhor qualidade e preço, inclui em seu poder de escolha a variável ambiental, dando preferência a produtos e serviços que não agridam o meio ambiente, tanto na produção quanto na distribuição, no consumo e no descarte final.

Diante disso, Elkington e Hailes (1988), já diziam que basta apenas compreender como as decisões de compra podem afetar o meio ambiente, não precisando reduzir drasticamente as compras a um mínimo, mas sim decidir por produtos mais sustentáveis.

Dessa forma, deve-se olhar toda a cadeia de um determinado produto, desde o processo de fabricação, olhando, por exemplo, a quantidade de água se gasta, passando pelo processo de distribuição, pelo uso e, em seguida, pelo descarte, garantindo que terá o destino correto ou até mesmo ser reaproveitado, sendo a melhor opção.

Além disso, segundo o Ministério do Meio Ambiente (2005), promover o consumo verde em países em desenvolvimento significa que primeiro deve-se garantir às populações de baixa renda acesso ao consumo de produtos e serviços que atendam às suas necessidades básicas, para que apenas aqueles que já possuem condições de garantir essas necessidades melhorem suas escolhas, escolhendo produtos e serviços ecologicamente corretos e socialmente justos.

\subsubsection{Consumo Sustentável}

Em relação a esse tópico, o consumo sustentável é consumir melhor e menos, levando em consideração os impactos ambientais, sociais e econômicos desde a compra até o descarte do produto (VACCARI, 2014).

Esse conceito surgiu após reconhecerem alguns limites sobre o consumo verde, mostrando que as mudanças deveriam vir de ações coletivas e mudanças políticas e institucionais. Portanto, o conceito de consumo sustentável é mais amplo que o de consumo verde, uma vez que, além das inovações tecnológicas e das mudanças das escolhas de consumo, ele também enfatiza ações coletivas e mudanças políticas, econômicas e institucionais. 
Desta forma, a estratégia política do consumo sustentável poderia funcionar como uma maneira de trazer problemas coletivos para a vida pessoal, aproximando as esferas privada e pública. (PORTILHO, 2004).

Além disso, segundo Cortez e Ortigoza (2007), o consumo sustentável tem como essência principal motivar uma consciência ecologicamente seletiva nos consumidores, em que estes criem hábitos de consumo mais responsáveis e com o menor desperdício possível. O consumo sustentável é uma ação preventiva em relação à educação ambiental.

\title{
2.3. Revolução Verde
}

A Revolução Verde surgiu durante a Guerra Fria com o objetivo de acabar com a fome no mundo, vista como consequência do crescimento populacional alinhado à má distribuição dos alimentos por meio do aumento da produção agrícola decorrente de novas tecnologias. Entre essas tecnologias estão a implementação do uso de máquinas no campo, o desenvolvimento de sementes geneticamente modificadas, além do uso de fertilizantes e agrotóxicos, visando o aumento da produtividade em um curto espaço de tempo.

\begin{abstract}
Segundo Zamberlam e Froncheti (2001), os impactos ambientais, econômicos e sociais acarretados pela modernização da agricultura baseiam-se no uso intensivo dos pacotes tecnológicos, na mecanização do trabalho, na união entre agricultura e indústria, na seleção das espécies, na monocultura, no latifúndio e no consumismo desmedido, principalmente dos países desenvolvidos. Com relação à questão ambiental, pode-se destacar a erosão genética como sendo um dos processos de degradação provocado pela seleção das espécies e pelo desmatamento. O processo de modernização na agricultura acentuou a extinção de espécies, tanto animais, quanto vegetais, por ter se dedicado a produtos, economicamente mais rentáveis (Andrades e Ganimi, 2007).
\end{abstract}

Todos esses impactos da Revolução Verde foram agravados no decorrer dos anos e, hoje em dia, como já falado em tópicos anteriores deste estudo, vemos que, caso não ocorra uma mudança de atitude da sociedade, os recursos naturais se esgotarão muito mais rápido.

\subsection{Sistemas Agrícolas}

Os sistemas agrícolas englobam as atividades referentes à agricultura e à pecuária. Esses sistemas são divididos em intensivo e extensivo, porém, sistemas alternativos têm ganhado espaço cada vez mais. 


\subsubsection{Sistema Agrícola Intensivo}

De acordo com Krajewski, Guimarães e Ribeiro (2003), o sistema agrícola intensivo é caracterizado pela prática em propriedades menores, utilizando pouca mão de obra e fortes investimentos em mecanização e tecnologias.

Além disso, uma das principais características desse sistema é o uso de agrotóxicos e fertilizantes em grande quantidade, o que, além de fazer mal à saúde, empobrece os solos.

Outro fator característico dessa produção é a monocultura, ou seja, o plantio de um único produto agrícola. As monoculturas também são grandes responsáveis pelos danos ao solo, uma vez que retira a cobertura vegetal, causando desequilíbrio ecológico.

\subsubsection{Sistema Agrícola Extensivo}

O sistema agrícola extensivo é a prática em grandes ou pequenas extensões de terras, em geral com baixos investimentos, com pouca ou muita utilização de mão de obra e nenhuma especialização. (KRAJEWSKI, GUIMARÃES, RIBEIRO, 2003.).

Este é um sistema caracterizado pela agricultura familiar, em que são utilizadas técnicas rudimentares e produção em baixa escala, tendo como foco o mercado interno ou de subsistência. Porém, mesmo que em menor quantidade em comparação com o sistema agrícola intensivo, essa produção também utiliza agrotóxicos.

\subsubsection{Sistemas Agrícolas Alternativos}

Em contrapartida aos métodos tradicionais de agricultura, surgiram sistemas mais sustentáveis para fazer a reconexão do homem com a terra. Dentro desses sistemas estão a agricultura orgânica, a agricultura biodinâmica, agricultura biológica, a permacultura e os sistemas agroflorestais (SAFs).

A mais comum é a agricultura orgânica, a qual é caracterizada pela não utilização de agrotóxicos e alimentos transgênicos. Essa forma de agricultura, além de deixar o alimento mais rico em nutriente, sendo mais saudável, também é uma das formas mais sustentáveis, uma vez que não agride o solo com insumos químicos.

Segundo Carlos Eduardo Lobo (2019), a agricultura biodinâmica surgiu na década de 1920 com base nas ideias do austro-húngaro Rudolf Steiner (1861-1925), que desenvolveu na virada do século XX a antroposofia ou ciência espiritual antroposófica. Esta é uma forma de agricultura orgânica que junta conceitos de química, geologia e astrologia, estudando como os astros influenciam no cultivo das plantas. Além disso, nesse método os animais são integrados de forma que os alimentos sejam reaproveitados, ou seja, todos os nutrientes que os animais comem acabam voltando para a terra de forma natural. 
Em 1930, Hans Peter Muller criou o conceito de agricultura biológica, a qual também não faz a utilização de insumos químicos. Este é um método de produção holístico que tem como principal técnica um sistema de rotação, promovendo a plantação de espécies variadas e adequadas para cada tipo de solo e clima.

A permacultura surgiu na década de 70 por Bill Mollison e David Holmgren, sendo um sistema para criação de comunidades sustentáveis, integrando ecologia e design. Segundo Mollison (1999), a permacultura é a elaboração e implantação de ecossistemas produtivos que mantenham a diversidade e a estabilidade dos ecossistemas naturais, promovendo energia, moradia e alimentação humana de forma a não impactar o meio ambiente negativamente.

Por fim, os sistemas agroflorestais são caracterizados, de acordo com o Embrapa (Empresa Brasileira de Pesquisa Agropecuária), pela introdução e interação de espécies arbóreas às culturas agrícolas e criação animais. Esta é uma técnica que permite a recuperação dos solos, controlando ervas daninha onde uma espécie é capaz de ajudar a outra de forma natural.

\subsection{Alimentação Sustentável}

A alimentação sustentável ainda é um termo pouco usado, mas se traduz em olhar com mais atenção à cadeia da produção dos alimentos e seus impactos no meio ambiente.

De acordo com Murilo Canova (2016), este é um conceito que procura diminuir o nível de impacto em um ambiente do início da produção, plantio, colheita ou extração, embalagem até a distribuição para, assim, evitar problemas como erosão do solo, contaminação da água, assoreamento de rio, entre tantos outros problemas neste estudo já abordados.

Além disso, a alimentação sustentável promove o aproveitamento dos alimentos de forma integral, como a utilização de cascas, talos, sementes e folhas, os quais são descartados quase sempre. 


\section{Metodologia do Estudo}

Este capítulo tem como finalidade apresentar a metodologia de pesquisa usada para coletar e, posteriormente, analisar os dados. Para melhor entendimento, essa sessão será dividida em cinco etapas, a serem elas: coleta de dados; fontes de informação selecionadas; procedimentos e instrumentos utilizados; formas de tratamento e análise dos dados; e, por fim, limitações do método.

\subsection{Coleta de dados}

O presente estudo trata de um assunto que vem ganhando cada vez mais visibilidade, mas ainda é pouco explorado, o que torna difícil formular hipóteses com precisão. Dessa forma, o método utilizado para a coleta de dados foi a pesquisa exploratória, uma vez que é utilizada para casos como esse.

De acordo com Gil (2007), a pesquisa exploratória é desenvolvida com o objetivo de proporcionar visão geral, do tipo aproximativo, para determinado fato. Além disso, esse tipo de pesquisa constitui a primeira etapa de uma investigação mais ampla, o que torna necessário o esclarecimento e delimitação acerca do tema por meio de discussão com pessoas envolvidas no assunto e revisão de literatura.

A primeira etapa foi realizada com o intuito de selecionar as pessoas para participarem da entrevista qualitativa. Tal etapa foi feita através de um questionário com perguntas fechadas, o qual tinha como finalidade analisar o nível de conhecimento dos entrevistados em relação aos impactos ambientais causados pela alimentação.

A segunda etapa foi realizada por meio de uma entrevista qualitativa, uma vez que esse procedimento consegue obter dados mais aprofundados, sendo possível a adaptação das perguntas e esclarecimento de possíveis dúvidas, conseguindo respostas mais específicas sobre o tema. Essa etapa da pesquisa foi realizada com um público restrito, em que participaram apenas as pessoas que tinham conhecimento de setenta por cento $(70 \%)$ dos dados apresentados na pesquisa da primeira etapa.

\subsection{Fontes de informação selecionadas}


A primeira etapa, como falado anteriormente, foi realizada através de um questionário estruturado com perguntas do tipo fechadas, onde foram apresentados os principais problemas ambientais causados pela alimentação. Essa etapa serviu como filtro para seleção do público a ser entrevistado. Para que as perguntas fossem formuladas, foram realizadas pesquisas acerca do tema, principalmente em artigos científicos e livros. A principal ferramenta para obtenção de dados em artigos foram os portais CAPES e Google Scholar.

A segunda etapa foi constituída de dados através de entrevistas mais profundas com pessoas selecionadas a partir da primeira etapa. Tais pessoas têm interesse e conhecimento sobre os impactos ambientais apresentados, causados pela forma que se alimentam.

Ao todo, nessa fase, foram entrevistadas vinte e quatro pessoas, tendo como única restrição o nível de conhecimento sobre os impactos ambientais. Segue na tabela abaixo o perfil dos entrevistados:

Tabela 1 - Perfil dos Entrevistados

\begin{tabular}{|c|c|c|c|c|c|}
\hline \multicolumn{6}{|c|}{ Perfil dos Entrevistados } \\
\hline $\mathbf{N}$ & Idade & Sexo & Escolaridade & Estado & Profissão \\
\hline $\mathrm{X} 1$ & 51 anos & Feminino & Graduação & São Paulo & Analista de Sistemas \\
\hline $\mathrm{X} 2$ & 21 anos & Feminino & Graduação & Rio de Janeiro & Estudante \\
\hline $\mathrm{X} 3$ & 22 anos & Feminino & Graduação & Rio de Janeiro & Estudante \\
\hline $\mathrm{X} 4$ & 20 anos & Feminino & Graduação & São Paulo & Estudante \\
\hline $\mathrm{X} 5$ & 23 anos & Feminino & Graduação & São Paulo & Estudante \\
\hline $\mathrm{x} 6$ & 19 anos & Feminino & Graduação & Rio de Janeiro & Estudante \\
\hline $\mathrm{X} 7$ & 25 anos & Feminino & Graduação & Rio de Janeiro & Estudante \\
\hline $\mathrm{X} 8$ & 23 anos & Feminino & Graduação & São Paulo & Publicitária \\
\hline$\times 9$ & 17 anos & Masculino & Ensino Médio & São Paulo & Estudante \\
\hline $\mathrm{X} 10$ & 22 anos & Feminino & Graduação & São Paulo & Cozinheira \\
\hline $\mathrm{X} 11$ & 35 anos & Masculino & Graduação & Rio de Janeiro & Fisioterapeuta \\
\hline $\mathrm{X} 12$ & 31 anos & Feminino & Graduação & Rio de Janeiro & Dentista \\
\hline $\mathrm{X} 13$ & 55 anos & Feminino & Graduação & São Paulo & Empresária \\
\hline $\mathrm{X} 14$ & 24 anos & Feminino & Graduação & Rio de Janeiro & Estudante \\
\hline $\mathrm{X} 15$ & 23 anos & Masculino & Graduação & Rio de Janeiro & Estudante e professor de yoga \\
\hline $\mathrm{X} 16$ & 20 anos & Masculino & Graduação & São Paulo & Estudante \\
\hline $\mathrm{X} 17$ & 51 anos & Feminino & Pós Graduação & Rio de Janeiro & Empresária \\
\hline $\mathrm{X} 18$ & 22 anos & Feminino & Graduação & Minas Gerais & Estudante \\
\hline $\mathrm{X} 19$ & 22 anos & Feminino & Graduação & Rio de Janeiro & Estudante \\
\hline $\mathrm{X} 20$ & 20 anos & Feminino & Graduação & Minas Gerais & Estudante \\
\hline $\mathrm{X} 21$ & 18 anos & Feminino & Ensino Médio & São Paulo & Estudante \\
\hline $\mathrm{X} 22$ & 21 anos & Feminino & Graduação & Rio de Janeiro & Estudante \\
\hline $\mathrm{X} 23$ & 24 anos & Masculino & Graduação & São Paulo & Estudante \\
\hline$X 24$ & 22 anos & Masculino & Graduação & Rio de Janeiro & Estudante \\
\hline
\end{tabular}


Em sua maioria, as entrevistas foram realizadas por telefone, por questão de facilidade, apenas algumas foram feitas pessoalmente. Os entrevistados são dos estados de São Paulo, Minas Gerais e Rio de janeiro, por questão de acessibilidade.

\subsection{Procedimentos e instrumentos utilizados}

Como coleta de dados, a estrutura da entrevista qualitativa exploratória utilizada foi a entrevista focalizada, uma vez que esse tipo de entrevista tem como intenção a coleta de dados de um tema específico, porém o entrevistado pode falar de forma livre e mais informal. Segundo Gil (2007), a entrevista focalizada é empregada com o objetivo de explorar e analisar experiências vividas em condições precisas, como é o caso desse estudo.

O roteiro da entrevista foi semi-estruturado de forma a entender a relação do entrevistado com as questões ambientais e alimentação, para que pudesse ser analisado o comportamento dele enquanto consumidor. Dessa forma, foram abordados temas como atitudes sustentáveis que o entrevistado tem; relação da alimentação com problemas ambientais; e mudança de hábitos alimentares. O roteiro da entrevista se encontra no Anexo um.

\subsection{Formas de tratamento e análise de dados}

Como as entrevistas foram feitas por telefone ou pessoalmente, o primeiro passo para a análise de dados foi a transcrição das entrevistas, para que pudesse facilitar o processo de análise.

O segundo passo foi separar as perguntas feitas por categorias tais quais: interesse por questões ambientais; atitudes sustentáveis; relação da alimentação com os problemas ambientais; mudança de comportamento; consumo; alimentos orgânicos; e aproveitamento de alimentos. Dessa forma, foi possível analisar cada entrevista por parte, sendo possível fazer uma comparação entre os entrevistados.

Após esse cruzamento de informações, o problema do estudo foi revisto e, com base no referencial teórico, foi feita a análise das respostas dos entrevistados. Essa análise consistiu em uma nova separação das respostas, agora de acordo com os temas que serão vistos no próximo capítulo referente à análise dos dados. Dessa forma, com base nos objetivos do estudo, foi feita a interpretação dos dados de forma que as respostas dos entrevistados referentes a cada assunto estivessem no mesmo local, possibilitando uma análise e comparação das informações de forma mais prática. 


\subsection{Limitações do método}

De acordo com Gil (2007), entre as principais limitações do método utilizado para obtenção de dados do presente estudo estão: o fornecimento de respostas falsas, determinadas por razão consciente ou inconsciente; a influência do aspecto pessoal do entrevistador sobre o entrevistado; a influência das opiniões pessoais do entrevistador em relação às respostas do entrevistado; a falta de motivação do entrevistado para responder as perguntas, uma vez que leva mais tempo e demanda certa profundidade.

Além disso, por se tratar de uma pesquisa com um número limitado de pessoas, devese tomar o cuidado para não generalizar os resultados, uma vez que a realidade dos entrevistados pode ser diferente da realidade do restante da sociedade. 


\section{Apresentação e análise dos resultados}

Este tópico apresenta os resultados dos dados adquiridos através da entrevista qualitativa, analisando as informações a partir das principais ideias do referencial teórico. Para um melhor entendimento dos dados, essa sessão foi dividida nos seguintes tópicos: questões ambientais e atitudes sustentáveis de consumo; relação da alimentação com os problemas ambientais; mudança no comportamento do consumidor; alimentação sustentável e o papel do consumidor.

\subsection{Questões ambientais e atitudes sustentáveis de consumo}

Este primeiro ponto para a análise de dados serviu para introduzir os entrevistados ao tema principal de estudo: a alimentação e seus impactos ambientais. Dessa forma, as duas primeiras perguntas do roteiro da entrevista foram referentes ao interesse do entrevistado em relação às questões ambientais em geral e quando isso começou, e às atitudes sustentáveis que eles têm diariamente. Nesse primeiro ponto, o foco não foi o tema alimentação.

Este primeiro tema foi escolhido com o intuito de entender se assuntos relacionados ao meio ambiente já estão incluídos de forma cotidiana na vida dos entrevistados e se são formas de pensamentos recentes. Além disso, outro propósito foi ver como o entrevistado entende e age em relação ao tema sustentabilidade.

Cortez e Ortigoza (2007) já diziam que o principal intuito do consumo sustentável é promover a consciência ecológica nos consumidores a partir de hábitos de consumo mais responsáveis e com o menor desperdício possível. Este pensamento vai ao encontro com as respostas dos entrevistados, uma vez que todos apresentam atitudes individuais para diminuir seu impacto ambiental.

Entre as respostas, os temas que surgiram foram, principalmente, a questão do lixo, evidenciando assuntos como descarte correto, coleta seletiva e não utilização ou diminuição de embalagens descartáveis, a reutilização e ressignificação de embalagens, o consumo consciente em relação à água e, por fim, temas relacionados à alimentação, principalmente o consumo da carne.

Além disso, a partir da análise das entrevistas, pode-se perceber que a maioria dos entrevistados começou a ter consciência dos impactos de suas atitudes a partir informações adquiridas de forma coletiva, principalmente nos colégios onde estudaram ou por meio de 
redes sociais, o que fez com que se interessassem pelo assunto e pesquisassem mais. Como mostram os entrevistados X10 e X24:

\footnotetext{
"Acho que sempre tive essa preocupação desde a época da escola. Desde criança tive boas orientações principalmente em relação à água e lixo." $(\mathrm{X} 10)$.

"Desde pequeno estudei em colégios que discutiam muito sobre essas questões, de certa forma sempre foi um interesse é um assunto constante na minha vida." (X24).
}

E é em relação a isso que Portilho (2004) apresentava a estratégia política do consumo sustentável, mostrando que os problemas coletivos deveriam ser trazidos para a vida pessoal, aproximando as esferas privada e pública.

\subsection{Relação da alimentação com os problemas ambientais}

Como já apresentado anteriormente, de acordo com a FAO, entre os cinco principais problemas ambientais dos dias de hoje, quatro deles têm como principal razão a alimentação e a forma de consumo das pessoas. Tendo isso como fato, a entrevista teve como um dos focos entender como o consumidor enxerga isso e se ele realmente acredita que existe essa relação direta.

Entre os vinte e quatro entrevistados, todos eles, sem exceção, afirmaram que a forma de se alimentar tem relação direta com os problemas ambientais, sendo realmente a principal causa. Os dois temas em comum que apareceram em quase todas as respostas foram a utilização de agrotóxicos e o agronegócio. Segue abaixo alguns trechos das respostas dos entrevistados:

\footnotetext{
"Eu acredito, sim, que a alimentação tem grande e direta relação com os problemas ambientais que estamos enfrentando. A escolha do que comemos gera consequência em toda a cadeia de produção, a qual impacta diretamente nos recursos naturais. Por exemplo, ao comprar um produto com agrotóxico, eu estou aceitando o seu uso e permitindo que o solo em que ele foi plantado seja contaminado. Além disso, o consumo de recursos naturais para produzir animais para abate é muito grande, portanto, optar por não comer produtos de origem animal é uma maneira de tentar evitar a degradação ambiental." (X18).

"Com certeza os principais problemas ambientais estão relacionados com a forma que a sociedade vem se alimentando e de acordo com os hábitos diários de consumo. A alimentação inconsciente ajuda o desmatamento abusivo, promovendo alimentos cheios de agrotóxicos, os quais ajudam na intoxicação e desequilíbrio de várias espécies, diminuição da camada de ozônio, impermeabilização dos solos, entre várias outras consequências." (X17).
} 
Além da questão gerada pelo uso dos agrotóxicos e atividades do agronegócio, outros fatores que surgiram foram a enorme produção de lixo durante todo o processo, desde a colheita ou fabricação, em caso de produtos industrializados, até a distribuição e descarte inadequado. Além disso, outro assunto que surgiu foi em relação às grandes empresas e à nossa cultura de consumo excessivo. Seguem trechos da fala de dois entrevistados:

\footnotetext{
"Para que os alimentos sejam feitos e embalados, em todos os processos acabam sendo geradas enormes quantidades de lixo, desde restos de alimentos até uso excessivo de embalagens. Dessa forma, podemos perceber que quanto mais processado o alimento, mais lixo será produzido. Além disso, quase sempre ocorre o descarte em local inadequado." (X4).

"A alimentação está constantemente presente durante toda a vida das pessoas e sua base exploratória e exaustiva como é proposta hoje determina o funcionamento de indústrias e o comportamento de mercados gigantescos. Os quais, por sua vez, diminuem questões ambientais em favor de ganhos econômicos. A sociedade possui hábitos alimentares insustentáveis e consumimos mais do que precisamos ou deveríamos." (X23).
}

Dessa forma, podemos analisar, por exemplo, que os efeitos da Revolução Verde, onde toda essa cultura de exploração para o consumo e aumento da produtividade, sem levar em consideração os impactos diretos ou indiretos no meio ambiente aumenta cada vez mais. Porém, em contrapartida, o número de pessoas interessadas, engajadas e conscientes em relação a esses assuntos também vem crescendo de forma exponencial.

\subsection{Mudança no comportamento do consumidor em relação à dieta alimentar}

Este item procurou responder o principal objetivo do estudo: entender se há mudança no comportamento do consumidor após o conhecimento dos impactos negativos no meio ambiente causados pela forma que a sociedade vem se alimentando.

Para isso, o principal ponto de discussão foi em relação às dietas que os entrevistados seguem, entre elas: a dieta onívora, caracterizada pela alimentação normal, sem nenhuma restrição; a dieta vegetariana, caracterizada pelo não consumo de nenhum tipo de carne; e a dieta vegana, conhecida também como vegetariana restrita, fundamentada pelo não consumo de nenhum tipo de produto derivado de animais, como carnes, leites e ovos. A escolha desse tema sobre a dieta que o entrevistado possui foi escolhida em razão de todos os problemas ambientais já apresentados em relação ao consumo de produtos de origem animal. 
De acordo com a Sociedade Vegetariana (2018), no Brasil, 14\% da população se declara vegetariana, mostrando um crescimento de $75 \%$ em relação ao ano de 2012 . Além disso, de 2012 para 2017, o número de buscas na internet pelo termo "vegano" aumentou 14 vezes no Brasil. Esses dados de crescimento estão de acordo com o perfil dos entrevistados, uma vez que a maioria se declara vegetariana ou vegana. Além disso, quase todos os entrevistados que seguem a dieta onívora afirmam que têm interesse em mudar para uma alimentação sem produtos derivados de animais, como se pode ver nas falas dos entrevistados X14, X22 e X24:

\begin{abstract}
"Eu tenho vontade de mudar, sim, justamente por todas as consequências que tal alimentação ocasiona, mas acredito que a mudança seja possível aos poucos." (X22).

"Eu tenho muita vontade de mudar para uma alimentação vegetariana ou vegana por entender que é uma questão de equilíbrio, qualidade de vida (saúde), causa social e ambiental, e principalmente, responsabilidade com o planeta." (X24).

"Eu sigo uma alimentação onívora, mas tenho, sim, interesse em mudar e, por essa razão, já não como mais carne vermelha. Eu quero mudar, pois acredito que os animais também têm sentimentos, como os humanos. Isso sem contar no impacto negativo ambiental e para a saúde que a forma de criação dos animais hoje em dia pode causar." (X14).
\end{abstract}

Outro ponto que ficou evidente na fala acima em relação à entrevistada X14 foi em relação ao motivo da escolha para mudança de alimentação, que, nesse caso, seria a compaixão pelos animais. Dessa forma, a pesquisa buscou analisar se os entrevistados que se consideram vegetarianos ou veganos tiveram essa mudança após o conhecimento sobre os impactos ambientais ou se tiveram algum outro motivo como a questão do sofrimento e exploração animal ou questões relacionadas à saúde.

A maioria dos vegetarianos e veganos entrevistados tiveram como principal motivação para a mudança a questão ambiental, dizendo que começaram a se interessar pelo assunto, principalmente, através de documentários e pesquisas. Além disso, houve um caso em que a mudança de alimentação e o conhecimento dos problemas ambientais ocorreram de forma simultânea:

\footnotetext{
"A minha mudança de alimentação e a consciência dos impactos negativos ao meio ambiente aconteceram de forma simultânea: quanto mais eu me informava a respeito dos problemas, mais me afastava da perspectiva de animais serem comida. Eliminei carnes vermelhas e uma semana depois não comia mais nenhum animal. Quatro anos depois, comecei a criticar meu próprio consumo de derivados e há três meses venho tentando parar de consumi-los." (X20).
} 
A pesquisa também buscou entender se os entrevistados que são onívoros, mesmo não mudando sua dieta, tiveram alguma mudança na sua alimentação e, em quase todos os casos, isso aconteceu. Seguem abaixo trechos de falas dos entrevistados em relação a isso:

\begin{abstract}
"Mesmo não mudando totalmente, eu diminui o consumo de carne vermelha, preferindo sempre carnes brancas. Além disso, aumentei meu consumo de vegetais e legumes, reduzindo a compra de produtos industrializados e fast food." (X5).

"Depois de saber um pouco mais dos impactos da alimentação, como sou cozinheira, tento honrar e valorizar ainda mais o ingrediente na hora de preparar e busco comprar de forma consciente, preferindo sempre produtores locais e produtos da estação. Outra mudança foi em relação às partes dos alimentos, tento sempre aproveitar ele ao máximo, de forma a diminuir o desperdício." (X10).
\end{abstract}

"Eu fui vegetariano durante alguns meses e, mesmo que tenha voltado a comer ovos e carne, sempre que possível evito a carne vermelha." (X24).

Entretanto mesmo com a grande maioria entrevistada sendo vegetariana ou vegana, além de onívoros querendo mudar, tiveram casos em que, mesmo a pessoa sabendo dos impactos ambientais e todos os outros problemas em relação à alimentação, dizem não ter interesse em mudar, como é o caso dos entrevistados X8 e X16:

\footnotetext{
"Não tenho interesse em mudar a forma como me alimento principalmente pela dificuldade de me adaptar com a dieta, uma vez que tenho muitas restrições - mas não por doença e sim por gosto." (X16ł).

"Eu sou onívoro e não tenho interesse em mudar, pois apesar de achar correto e saber de todos os impactos negativos, meu paladar não é muito chegado em alimentos naturais, como verduras, legumes e frutas." (X8).
}

Dessa forma, podemos perceber que mesmo tendo informações e sabendo das consequências de suas escolhas, o prazer de comer certos alimentos e a preguiça por mudanças às vezes acabam tendo mais peso do que os impactos ambientais e outros fatores.

\title{
4.4. Papel do consumidor em relação aos produtos orgânicos e desperdício de alimentos
}

Como já apontado anteriormente, além dos impactos ambientais causados pela produção de carnes e outros produtos de origem animal, outros aspectos são os problemas causados pelo uso incessante de agrotóxicos e o desperdício de alimentos em toda sua 
cadeia de produção, distribuição e uso final inadequado. Dessa forma, esse item trata da análise referente a esses dois outros temas.

Em relação ao uso de agrotóxicos, a entrevista buscou entender onde os entrevistados geralmente compram seus alimentos, chegando ao assunto referente ao consumo de alimentos orgânicos e de produtores menores e locais. Dessa forma, foi analisado se eles compram em supermercados, feiras normais ou em feiras orgânicas.

Todos os entrevistados fazem compras, ou a maior parte delas, nos supermercados e a razão disso, na maioria das vezes, foi pela questão da praticidade e localização, como se pode ver nos trechos abaixo:

\footnotetext{
"Os lugares onde compro variam muito, mas a maioria acaba sendo em supermercados convencionais em razão da praticidade, falta de opção de mercados orgânicos e pelo péssimo hábito criado pela sociedade. Moro no interior e não tenho muitas opções". (X4)

"Não sou eu quem faz as compras de casa. Mas meus pais costumam comprar em supermercados por conta da facilidade, proximidade de casa, variedade e preço. Acho que o principal ponto dessa decisão é pela falta de tempo e conveniência." (X19).
}

A maioria dos entrevistados, mesmo fazendo compras em supermercados, também fazem compras em feiras normais, optando sempre por comprar a maioria dos alimentos com produtores menores. Entretanto, quase todos os entrevistados não frequentam feiras orgânicas e as principais razões disso são os preços mais elevados se comparados a outros locais e por não acharem com facilidade perto de onde moram. Os poucos entrevistados que costumam comprar em feiras orgânicas mostram que seus principais motivos são o incentivo ao pequeno produtor e a diminuição dos impactos ambientais.

\begin{abstract}
"Dos alimentos que eu compro $70 \%$ deles compro em feiras orgânicas. Mesmo que não tenha nenhuma feira orgânica perto da onde eu moro, eu faço questão de ir ao local mais próximo que ache, uma vez que essas feiras incentivam os produtores locais, reduzem mais ainda o impacto ambiental por não utilizarem agrotóxicos na produção e, portanto, só se encontram produtos que estão na época. Além disso, quando se compra de grandes produtores, as distâncias a serem percorridas para os produtos chegarem aos locais de venda são enormes e dessa forma, emitem muito mais $\mathrm{CO} 2$ que comprar em feiras." (X2).
\end{abstract}

Dessa forma, podemos perceber que aqueles que realmente se importam com os impactos ambientais acabam fazendo o possível para consumirem da forma mais consciente e justa possível.

Através da pesquisa, conseguiu-se perceber que quase todos os entrevistados não consideram os produtos orgânicos como inacessíveis para a realidade deles, porém afirmam que, para a realidade da grande maioria da população brasileira, a compra de produtos 
orgânicos é, sim, inacessível, em sua maior parte em razão do preço e disponibilidade. Seguem abaixo algumas afirmações dos entrevistados:

\begin{abstract}
"A compra de produtos orgânicos não é acessível para todas as classes sociais, por conta do valor de mercado. É muito complicado você falar para uma pessoa da comunidade que ela precisa consumir alimentos orgânicos, quando ela luta para sobreviver comprando os legumes mais em conta do mercado. Acredito que para a classe média alta é um pouco mais acessível em razão da questão financeira." (X2).

"Inacessível para alguns, sim. A maior parte disso por conta do preço e da disponibilidade, na Zona Sul da cidade existem muito mais estabelecimentos que vendem esses tipos de produtos." (X7).

"Na realidade em que vivo, não são inacessíveis, mas percebo e compreendo a dificuldade de escolher e comprar um produto mais caro por ser orgânico para quem não tem informação sobre ou preocupação com o tema." (X10).

"Em minha opinião, considero os produtos orgânicos ainda bem elitizados, uma vez que existem poucos produtores, os quais não conseguem competir com preço de mercado, afastando grandes canais de distribuição e a maioria da população." (X24).
\end{abstract}

Com todos esses pontos, podemos analisar que mesmo as pessoas tendo conhecimento e consciência dos impactos negativos ao meio ambiente, a grande maioria ainda não mudou sua forma de comprar os alimentos, não dando preferência aos alimentos orgânicos.

Outra questão debatida nas entrevistas foi em relação ao desperdício e aproveitamento integral dos alimentos. Como falado anteriormente, de acordo com a FAO, apenas um quarto do que é desperdiçado nos Estados Unidos e na Europa, conseguiria alimentar 800 milhões de pessoas, mostrando que a maior parte dos alimentos não é consumida de maneira sustentável. Este fato vai ao encontro com quase todas as respostas dos entrevistados, uma vez que afirmaram não utilizar todo o alimento quando cozinham, jogando sempre fora as partes dos alimentos que poderiam ser reaproveitadas, como talos, cascas, folhas e sementes. Além disso, quase todos os entrevistados disseram que jogam essas partes no lixo comum, o que mostra que o descarte em locais inadequados ainda é a realidade da maioria da população. 


\section{Conclusões}

Este estudo pretendeu analisar o comportamento do consumidor em relação aos impactos ambientais ocasionados pela forma de consumo alimentar que a sociedade tem hoje em dia. Dessa forma, procurou-se analisar se as pessoas realmente mudam sua alimentação para diminuir seu impacto. O foco do estudo recaiu em entender quais são os interesses e as principais atitudes sustentáveis dos consumidores; qual era o entendimento dos consumidores sobre a relação da alimentação com os problemas ambientais; e, principalmente, a mudança do comportamento referente ao seu consumo.

Como base, foram analisados diversos autores e conceitos referentes aos problemas ambientais causados pela alimentação, ao comportamento do consumidor, ao consumo consciente e suas variáveis, e à alimentação sustentável, para que, assim, pudessem auxiliar o desenvolvimento e entendimento do estudo.

Para complementar os referenciais teóricos analisados e responder a pergunta do estudo, a validação ocorreu através de entrevistas qualitativas. Ao todo, foram vinte e quatro pessoas entrevistadas, tendo como única limitação o conhecimento dos impactos ambientais causados pela alimentação.

Com a pesquisa, foi possível perceber que todos os entrevistados consideram a alimentação como principal causa dos problemas ambientais vistos hoje em dia. Entre as principais causas apontadas estão o uso de agrotóxicos no cultivo e as atividades do agronegócio, além de terem sido apontados problemas referentes à enorme produção de lixo e o desperdício de alimentos. Dessa forma, podemos ver que os temas que surgiram nas entrevistas foram os mesmos apontados no trabalho, mostrando ser um tema relevante a ser estudado, em que o número de pessoas interessadas e conscientes é crescente.

Outro ponto analisado com as entrevistas foi à relação da dieta dos entrevistados e as suas escolhas de consumo. Os temas referentes ao vegetarianismo e veganismo apareceram por conta dos gigantescos impactos do agronegócio e, com a pesquisa, foi possível perceber que os adeptos a esses movimentos estão crescendo, uma vez que mais da metade dos entrevistados se encontra nessas situações. Além disso, quase todos os outros que não seguem essas dietas têm consciência e querem mudar e, na maioria desses casos, já houve a diminuição do consumo de carnes, principalmente a vermelha e o aumento do consumo de verduras, legumes e frutas. 
Além disso, foi analisado através das entrevistas ${ }_{2}$ que o principal motivo para a escolha de uma dieta sem produtos de origem animal são os problemas ambientais, uma vez que oito dos treze vegetarianos/veganos entrevistados foram influenciados por essa razão. Dessa forma, conseguimos responder à principal pergunta do estudo, mostrando que há a mudança no comportamento do consumidor em relação aos impactos ambientais, pelo menos em relação à dieta e dentro da realidade dos entrevistados.

Já em relação ao uso de agrotóxicos, procurou-se entender onde os entrevistados costumam fazer suas compras e se dão preferência aos produtos orgânicos. Foi possível analisar que todos, sem exceção, fazem suas compras ou parte delas nos supermercados e que apenas cinco dos vinte e quatro entrevistados compram sempre em feiras orgânicas. Porém vale ressaltar que a maior parte dos entrevistados tem o costume de ir às feiras normais, fortalecendo os pequenos produtores.

A principal razão analisada para os entrevistados não consumirem produtos orgânicos foi pela questão da dificuldade em achar e pelo preço elevado. Mesmo a maioria afirmando que alimentos orgânicos são acessíveis para suas condições financeiras, eles mostram que para a maior parte da população do Brasil esse consumo é inacessível, o que mostra que a realidade de comportamento ainda não é de mudança nesse sentido.

O último ponto analisado foi a questão do desperdício e descarte dos alimentos, mostrando que quase todos os entrevistados não costumam utilizar o alimento de forma integral, mesmo sabendo que conseguem utilizar as demais partes e acabam jogando fora, em sua grande maioria, no lixo comum. Dessa forma, podemos perceber que o uso e descarte dos alimentos são inadequados em quase todos os casos.

Por fim, com a pesquisa foi possível analisar que mesmo a grande maioria mudando para uma dieta sem o consumo de produtos de origem animal, não houve uma mudança de comportamento em relação a outras atitudes, como a escolha de onde comprar, o desperdício no preparo dos alimentos e o descarte inadequado. Entretanto, surgiram casos que mostram que existem pessoas que consomem de forma consciente em todos os pontos discutidos, mesmo sendo uma parcela bem pequena.

Do ponto de vista gerencial, um dos pontos que puderam ser concluídos são que empresas devem investir cada vez mais em produtos do segmento vegetariano e vegano, uma vez que com a pesquisa pode-se confirmar o crescimento desse mercado e que mesmo pessoas não seguindo essa dieta, o interesse é muito grande. Além disso, empresas que vendem produtos orgânicos devem procurar novas formas de promoções, uma vez que as pessoas ainda não estão impactadas a ponto de comprarem com frequência ou de acharem importante. Além disso, essas empresas devem procurar vender apenas em supermercados de classe mais alta, visto que este é o público alvo. 


\subsection{Sugestões e recomendações para novos estudos}

Como desdobramentos futuros, há diversas oportunidades que ainda podem ser exploradas, uma vez que se trata de um estudo com tema de interesse crescente e atual.

- Fazer um estudo sobre a influência da classe social nas escolhas alimentares, visto que surgiram afirmações no estudo em relação à acessibilidade de produtos orgânicos.

- Entender melhor o motivo das pessoas ainda não consumirem produtos orgânicos mesmo dizendo ser acessível para a sua realidade.

- Aprofundar o conceito de consumo consciente na percepção do comportamento do consumidor em relação a esse tema. 


\section{Referências Bibliográficas}

Agricultura alternativa. Sua Pesquisa. Disponível em: $<$ https://www.suapesquisa.com/meio_ambiente/agricultura_alternativa.htm>. Acesso em: 22 mai. 2019.

ANDRADES, Thiago; GANIMI, Rosângela. Revolução verde e a apropriação capitalista. Juiz de Fora, 2007.2 Disponível em: <https://www.cesjf.br/revistas/cesrevista/edicoes/2007/revolucao_verde.pdf>. Acesso em: 12 mai. 2019.

BEM, Anderson. O problema do emprego dos conceitos de agricultura extensiva e intensiva nos livros didáticos de geografia. Ano 7, nov. 2010. Revista eletrônica da Associação dos Geógrafos Brasileiros. Disponível em: <http://seer.ufms.br/index.php/RevAGB/article/view/639/439>. Acesso em: 22 mai. 2019.

BLACKWELL; MINIARD; ENGEL. Comportamento do consumidor. 9 ed.

BRASIL. Governo Federal. Consumo sustentável: manual de educação. Brasília, 2005. Disponível

<http://www.mma.gov.br/estruturas/educamb/_arquivos/consumo_sustentavel.pdf>. Acesso em: 09 mai. 2019.

BRASIL. Ministério do Meio Ambiente. O que é consumo consciente? Disponível em: <http://www.mma.gov.br/responsabilidade-socioambiental/producao-e-consumosustentavel/consumo-consciente-de-embalagem/quem-e-o-consumidorconsciente/item/7591.html>. Acesso em 26 mai. 2019.

BROWN, L. Ecoeconomia - Construindo uma Economia para a Terra. Salvador: UMA, 2003.

CANOVA, M. Alimentação Sustentável: benefícios para você e o planeta. Ocean Drop, 19 mai. 2016.

Centro Paranaense de Referência em Agroecologia. Agricultura sustentável, os modelos alternativos. 19 dez 2016. Disponível em: <https://medium.com/centro-paranaense-derefer\%C3\%AAncia-em-agroecologia/agricultura-sustent\%C3\%A1vel-os-modelos-

alternativos-a19b90c2e565>. Acesso em: 22 mai. 2019.

COOPER, R. The Design Experience - The Role od Design and Designers in the 21 Century. Cornwall, Ashgate Publishing, 2002.

CÔRTES, Pedro; MORETTI, Sergio. Consumo verde: um estudo transcultural sobre 
crenças, preocupações e atitudes ambientais. Disponível em: <http://revistabrasileiramarketing.org/ojs-2.2.4/index.php/remark/article/view/2592/pdf_133>. Acesso em: 09 mai. 2019.

DOURADO,L. Consumo de animais selvagens deixa mais de 100 espécies à beira da extinção. ANDA, 27 dez. 2016.

DUARTE, Amanda. Revolução verde. Estudo Prático, 2014. Disponível em: <https://www.estudopratico.com.br/revolucao-verde/>. Acesso em: 26 mai. 2019.

DUTRA, Rodrigo; SOUZA, Murilo. Cerrado, revolução verde e evolução do consumo de agrotóxicos. Universidade Estadual de Goiás. Goiás, 2018. Disponível em: <http://www.seer.ufu.br/index.php/sociedadenatureza/article/view/36367/pdf_1>. Acesso em: 28 mai. 2019.

ELKINGTON, J; HAILES, J. The Green Consumer Guide. Londres, 1988.

Food sustainability index: a study on a global food sustainability. Barilla center. Disponível em: <https://www.barillacfn.com/en/food_sustainability_index/ >. Acesso em 23 mai. 2019.

FRIEND, G. The truth about Green Business. NJ: Natural Logic Inc, 2009.

GERHARDT, Marcos. Uma história ambiental da modernização da agricultura: o norte do Rio Grande do Sul. História: Debates e Tendências. v. 16, n.1, jan./jun, 2016. Disponível em: <http://seer.upf.br/index.php/rhdt/article/view/6264/3769>. Acesso em: 22 mai. 2019.

GIL, Antônio Carlos. Métodos e Técnicas de pesquisa social. 6ª ed. São Paulo: ATLAS, 2008.

GRIGORI, Pedro. Apicultores brasileiros encontram meio bilhão de abelhas mortas em três meses. Pública, 2019. Disponível em: <https://apublica.org/2019/03/apicultoresbrasileiros-encontram-meio-bilhao-de-abelhas-mortas-em-tres-meses/>. Acesso em: 22 mai. 2019.

IPOEMA: Instituto de Permacultura. Conceitos da Permacultura. Disponível em: <https://ipoema.org.br/2016/12/12/conceitos-da-permacultura/>. Acesso em: 22 mai. 2019.

LAZZARI, Francini; SOUZA, Andressa. Revolução verde: impacto sobre os conhecimentos tradicionais. Congresso Internacional de Direito e Contemporaneidades. Universidade Federal de Santa Maria, 2017. Disponível em: <http://coral.ufsm.br/congressodireito/anais/2017/4-3.pdf>. Acesso em 22 mai. 2019.

LUGLIO, Alessandra. Tendências em alimentação sustentável. 05 ago. 2016. Estadão. Disponível em: <https://sustentabilidade.estadao.com.br/blogs/alessandra-luglio/tendenciasem-alimentacao-sustentavel/>. Acesso em: 10 mai. 2019.

MOREIRA, Catarina. Agricultura Biológica. Revista Ciência Elementar, 2011. Disponível em: <https://rce.casadasciencias.org/rceapp/pdf/2013/003/>. Acesso em: 14 mai. 2019.

MOREIRA, Roberto José. Críticas Ambientalistas à Revolução Verde. Estudos Sociedade e Agricultura, 15 out. 2000. Disponível em: 
<https://revistaesa.com/ojs/index.php/esa/article/view/176/172>. Acesso em 10 mai. 2019.

O desenvolvimento regional sob a ótica da sustentabilidade: uma reflexão sobre a economia e o meio ambiente. Ágora: Revista de divulgação científica. Disponível em: $<$ https://www.researchgate.net/profile/Jorge_Alves/publication/268365833_O_DESENVOLVI MENTO_REGIONAL_SOB_A_OTICA_DA_SUSTENTABILIDADE_UMA_REFLEXAO_SOB RE_A_ECONOMIA_E_O_MEIO_AMBIENTE/links/56eae6dd08ae9̄dcdd82a56ab.pdf>. Acesso em: 13 mai. 2019.

O que é permacultura? UFSC. Disponível em: <http://permacultura.ufsc.br/o-que-epermacultura/>. Acesso em: 21 mai. 2019.

Organização das Nações Unidas para a Alimentação e a Agricultura. Food losses and waste in Latin America and the Caribbean. Julho, 2014. Disponível em: <http://www.fao.org/3/a-i3942e.pdf/>. Acesso em: 15 jun. 2018.

Organização das Nações Unidas para a Alimentação e Agricultura. FAO: Agronegócio foi responsável por quase $\mathbf{7 0} \%$ do desmatamento na América Latina. Santiago, Chile, 2016. Disponível em: <http://www.fao.org/americas/noticias/ver/pt/c/425810/>. Acesso em: 26 mai. 2019.

Panorama do consumo consciente no Brasil: desafios barreiras e motivações. Pesquisa AKATU 2018. Disponível em: <https://www.akatu.org.br/wpcontent/uploads/2018/11/pdf_versao_final_apresenta\%C3\%A7\%C3\%A3o_pesquisa.pdf >.

Acesso em: 12 mai. 2019.

Sociedade Vegetariana Brasileira. Meio Ambiente. Disponível em: <https://www.svb.org.br/vegetarianismo1/meio-ambiente>. Acesso em: 14 mai. 2019.

SOLOMON, M, R. O Comportamento do Consumidor - Comprando, Possuindo e Sendo. Porto Alegre: Bookman, 2016.

Toda Matéria. Alimentos Orgânicos. Disponível em: <https://www.todamateria.com.br/alimentos-organicos/>. Acesso em: 22 mai. 2019.

TRIGUEIRO, André. Closet: o santuário do consumo moderno. Disponível em: $<$ https://books.google.com.br/books?id=U4UzNDJiUz0C\&pg=PT25\&dq=consumo+conscient e\&hl=ptBR\&sa=X\&ved=0ahUKEwievoLeu8HiAhX3H7kGHXUZCDUQ6AEIMjAC\#v=onepage $\& q=$ consumo\%20 consciente\&f=false $>$. Acesso em 12 mai. 2019.

VACCARI, L, C. O hiato entre atitude e comportamento ecologicamente conscientes: Um estudo com consumidores de diferentes gerações. Rio de Janeiro, 2014. Dissertação (Doutorado em Administração) - Departamento de Administração: Pontifícia Universidade Católica do Rio de Janeiro.

WELLE, D. Os cinco maiores problemas ambientais do mundo e suas soluções. Carta Capital, 13 out. 2016. Disponível em: <https://www.cartacapital.com.br/sustentabilidade/oscinco-maiores-problemas-ambientais-do-mundo-e-suas-solucoes.> Acesso em: 28 mai. 2019. 


\section{Anexo - Roteiro de Entrevistas}

Bom dia/boa tarde/boa noite.

Eu sou aluna de administração da PUC-Rio e estou fazendo uma pesquisa para o meu TCC para analisar o comportamento do consumidor sobre os impactos ambientais relacionados à alimentação e gostaria muito da sua ajuda! Essa pesquisa foi dividida em duas etapas e a primeira delas foi o questionário já respondido por você. Agora, a segunda parte consiste em perguntas abertas! Muito obrigada desde já!

Idade:

Sexo:

Nível de Escolaridade:

Estado:

Profissão:

1. Quando você começou a se interessar por questões ambientais?

2. Quais atitudes sustentáveis fazem parte do seu dia a dia?

3. Você acredita que a alimentação tem grande relação com os problemas ambientais? Por que?

4. Que tipo de dieta você adota: onívora, vegetariana ou vegana?

5. *Caso seja onívora, você tem interesse em mudar? Por que?

6. *Caso seja vegetariana/vegana, qual foi o motivo da sua mudança?

7. Você mudou sua alimentação após o conhecimento dos problemas ambientais causados por ela? Quais foram suas mudanças?

8. Onde você costuma comprar seus alimentos: supermercados, feiras normais ou feiras orgânicas? Por que?

9. Sabendo que o uso indiscriminado de agrotóxicos causa danos na saúde e meio ambiente, você consome produtos orgânicos? Com que frequência?

10. *caso não consuma, qual seria a razão?

11. Você considera o consumo de alimentos orgânicos como inacessível? Por que? 
12. Você tem o hábito de aproveitar todo o alimento (incluindo talos, cascas, sementes e folhas) quando cozinha? Caso não, o que você faz com essas partes? 